Journal of Business Management and
Economic Research
2018, 2(11): 16-23 DOI: $10.29226 / \mathrm{TR} 1001.2018 .76$
Journal Homepage: https://www.jobmer.org

\title{
A Theoretical Study on the Application of the "Vertical Tax Equity"
}

\section{Rami Obeid}

Head of Data Analysis \& Management Division, Central Bank of Jordan, Amman, Jordan rami.obeid3@gmail.com

\begin{abstract}
This paper focuses on discussing the principle of "Vertical Tax Equity", theoretically and mathematically, by comparing between three rules: absolute sacrifice, proportional sacrifice, and marginal sacrifice. Vertical tax equity is based essentially on two principles: "Ability to pay" and "The amount of sacrifice" or "Loss of welfare" for every taxpayer. The study showed and illustrated how to make a comparison between the three rules above which may contribute to the design of the optimal tax system, and how governments may determine the "fair share" for taxpayers' contributions in its spending. Graphs and mathematical equations were used to illustrate how to find the optimal tax rate based on the loss of the welfare of taxpayers.
\end{abstract}

Keywords: Vertical Tax Equity, absolute sacrifice, proportional sacrifice, marginal sacrifice

\section{Introduction}

Several authors argued that the classical criteria of equals treated equally imply no rank reversal criterion (Feldstein, 1976; Plotnick, 1981; King, 1983). Atkinson (1970), Blackorby and Donaldson (1976), Sen (1973), Kondor (1975), Rosen (1978), Fields and Fei (1978), and King (1983) have pointed out that index measures of the income distribution should be consistent with a social welfare function. Some of these authors have provided indicators to determine how income is distributed, such as Gini coefficient and Atkinson's index. Later, a number of authors linked the subject of public finance and taxation to income distribution. However, they discussed how to achieve tax Equity in their literatures. Although it is difficult to access tax Equity, it is a basic criterion for tax structure design. Most people agree that the tax system should be fair in the sense that anyone who pays a tax must be involved in a "fair share" for government spending. Nevertheless, there is no agreement on the definition of this "fair share". In addition, there are two approaches that can be taken into consideration about tax equity:

a) An approach based on the so-called "benefit principle", based on Adam (Smith, A., 1776), where each taxpayer contributes in line with the benefits received from public services. 
According to this approach, the appropriate tax formula depends on the patterns of preference and, more specifically, on the elasticity of both income and price. If the income elasticity is high, the appropriate tax rates will rise with the income, but if the price elasticity is high, the rise will be lower. The relationship can be defined as follows:

$$
\begin{aligned}
& E y=\left(\frac{\Delta Q}{Q}\right) /\left(\frac{\Delta Y}{Y}\right) \text {-----(1) } \\
& E p=\left(\frac{\Delta Q}{Q}\right) /\left(\frac{\Delta P}{P}\right) \text {-----(2) }
\end{aligned}
$$

Where Ey: The elasticity of income, Ep: The elasticity of price, Y: Income, P: Price.

By dividing equation (1) with (2):

$$
\frac{E y}{E p}=\left(\frac{\Delta P}{P}\right) /\left(\frac{\Delta Y}{Y}\right)-----(3)
$$

The right side of equation (3) expresses the elasticity of the tax rate of income, which:

- Ey/Ep=1, The tax rate will be constant.

- Ey/Ep>1, The tax rate will be progressive.

- Ey/Ep<1, The tax rate will be regressive.

Therefore, the required structure for tax rate will be proportional, progressive, or regressive, which depend on whether income elasticity of demand for public goods equals, exceeds, or falls short of price elasticity.

The second approach is based on the principle of "ability to pay." Under this approach, each taxpayer contributes proportionately to its ability to pay. This approach is not easy to apply or even interpret. A clear mechanism must be found to measure the "capacity to pay" before applying this principle; thus, people of equal income pay the same amount of tax (horizontal equity), while those with higher incomes pay a higher tax (vertical equity) (Wise \& Berger, 2010) (TJNA, 2011).

Nevertheless, the difficulty here is how to develop a quantitative measure of ability to pay. This paper focuses on the second approach to the form of taxation, specifically the so-called "vertical Equity".

\section{Research Problem}

The study will examine how to achieve vertical tax equity theoretically. It will also seek to clarify the options available for selecting the appropriate tax system by linking tax equity to loss of income for taxpayers. Several studies such as (Holeckova, 2013) have shown that the tax system that seeks to raise revenue in ways that avoid distortion effects is considered neutral tax system. Furthermore, (Mostar\& Evan, 1995) argue that the taxpayer's awareness of the absence of tax equity negatively impacts on his decision to disclose his income.

\section{Importance of the Research}

The importance of the study lies on the importance of designing an appropriate tax system that achieves equity among taxpayers. A distortion of the tax system will negatively affect the 
economies of countries (Škreb, 1999). Also, there are some aspects that must be considered when designing a tax system, for example, (Güneş \& Polat, 2016) focus on the relationship between democracy and economic development over the concept of taxation. Furthermore, (Obeid \& Awad, 2018) shows that the 2008 global financial crisis highlighted the importance of maintaining financial stability. The discussion of monetary and fiscal policies is no longer separated from policies related to policies targeting to control systemic risk.

\section{Research Objectives}

The aim of this study is to provide a simplified theoretical framework on how to achieve vertical tax equity mathematically, and how to link the determination of the tax rate to the loss of welfare for taxpayers.

\section{Methodology}

In this study, graphs and mathematical equations will be used to illustrate how to find the optimal tax rate based on the loss of welfare of taxpayers.

\section{The concept of Vertical Equity}

The issue of vertical equity in taxation is linked to the so-called "Equal Sacrifice Rules" where taxpayers are treated equally if the tax includes equal loss of welfare, and loss of welfare is linked to loss of income. People with different income must pay different amounts of taxes, but the problem here is how to determine these amounts and how to interpret the concept of "equality" and whether equal loss requires progressive tax or not.

Therefore, the answer to the above questions depends on the form of the income benefit table and the base of the equal loss. Mill (1921) argued that taxpayers are said to be treated equally if their tax payments involve an equal sacrifice or loss of welfare. Here, equality can be interpreted to mean: absolute sacrifice, proportional sacrifice, or marginal sacrifice. These concepts can be interpreted in the following graph. The first graph illustrates the low income for the taxpayer $(\mathrm{L})$, while the second graph illustrates the high income of the taxpayer $(\mathrm{H})$. MUL \& $\mathrm{MU}_{\mathrm{H}}$ is the marginal utility of the income tables. The income before tax of $\mathrm{L}$ is $\mathrm{OB}$, while OB' is the income before tax for $\mathrm{H}$. In addition, the total utilities received by $\mathrm{L} \& \mathrm{M}$ are OBDM \& $\mathrm{OB}^{\prime} \mathrm{D}^{\prime} \mathrm{M} M$ respectively. So the question is: how can taxes be calculated under the three rules mentioned above? 
Figure 1. Measure of Equal Sacrifice
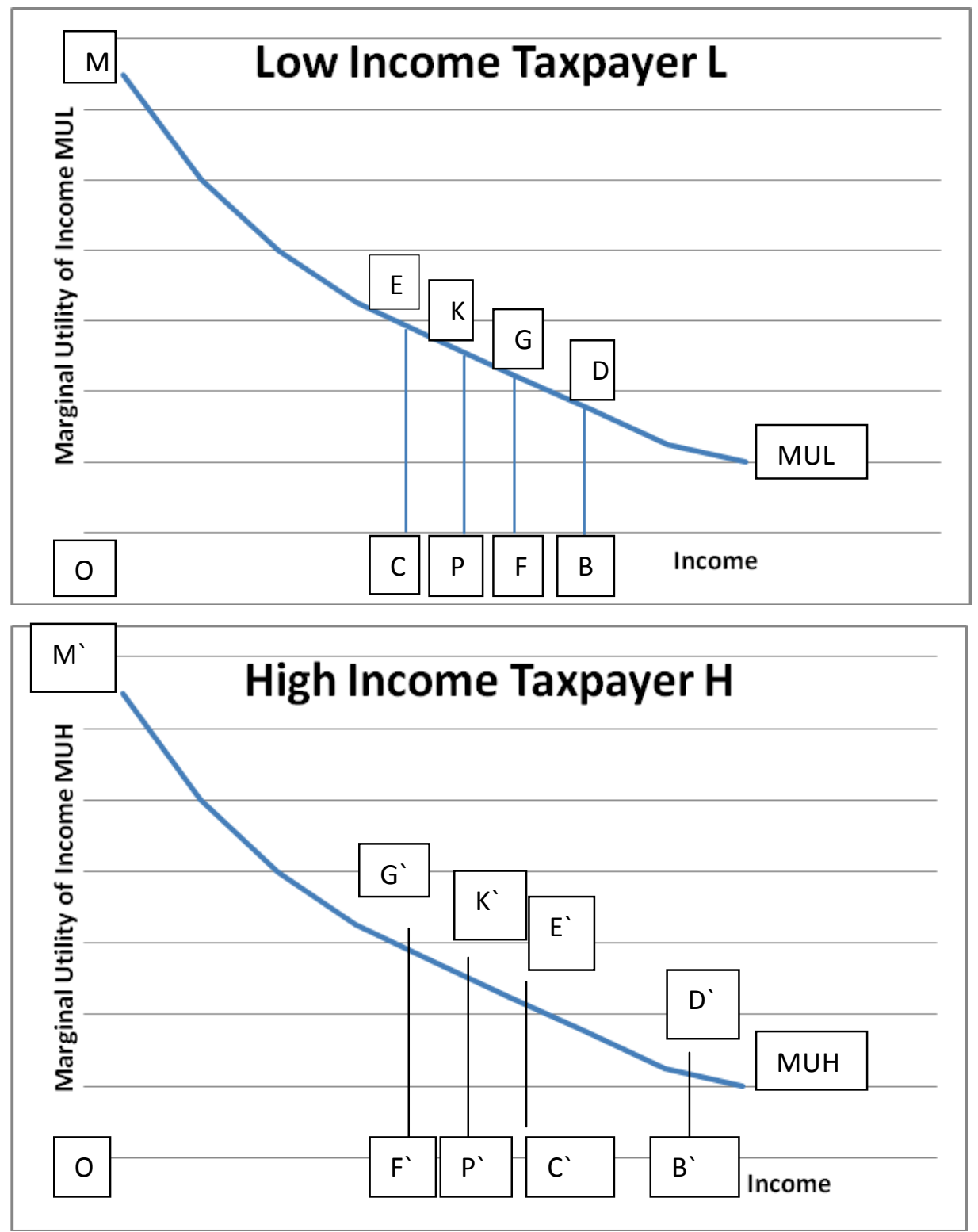

\subsection{Absolute Sacrifice}

Under the absolute sacrifice rule, $\mathrm{L}$ is the owner of the $\mathrm{OB}$ income pays $\mathrm{CB}$, whereas $\mathrm{H}$ is the owner of the $\mathrm{OB}^{\prime}$ income pays $\mathrm{C}^{\prime} \mathrm{B}$ '. Thus, the required tax returns are $\mathrm{CB}+\mathrm{C}^{\prime} \mathrm{B}{ }^{\prime}=\mathrm{T}$, the loss of welfare for $L$ is equal to CBDE while $H$ is equal to $C^{\prime} B^{\prime} D^{\prime} E$ ', and $T$ is also distributed so that $\mathrm{CBDE}=\mathrm{C}^{\prime} \mathrm{B}^{\prime} \mathrm{D} \mathrm{E}^{\prime}$.

If the marginal utilities for both taxpayers L\&H are constant and equal, the MU will be parallel to the x-axis; the absolute sacrifice will lead to the achievement of a regressive tax rate for all incomes. 
Figure 2. Measure of Equal Sacrifice
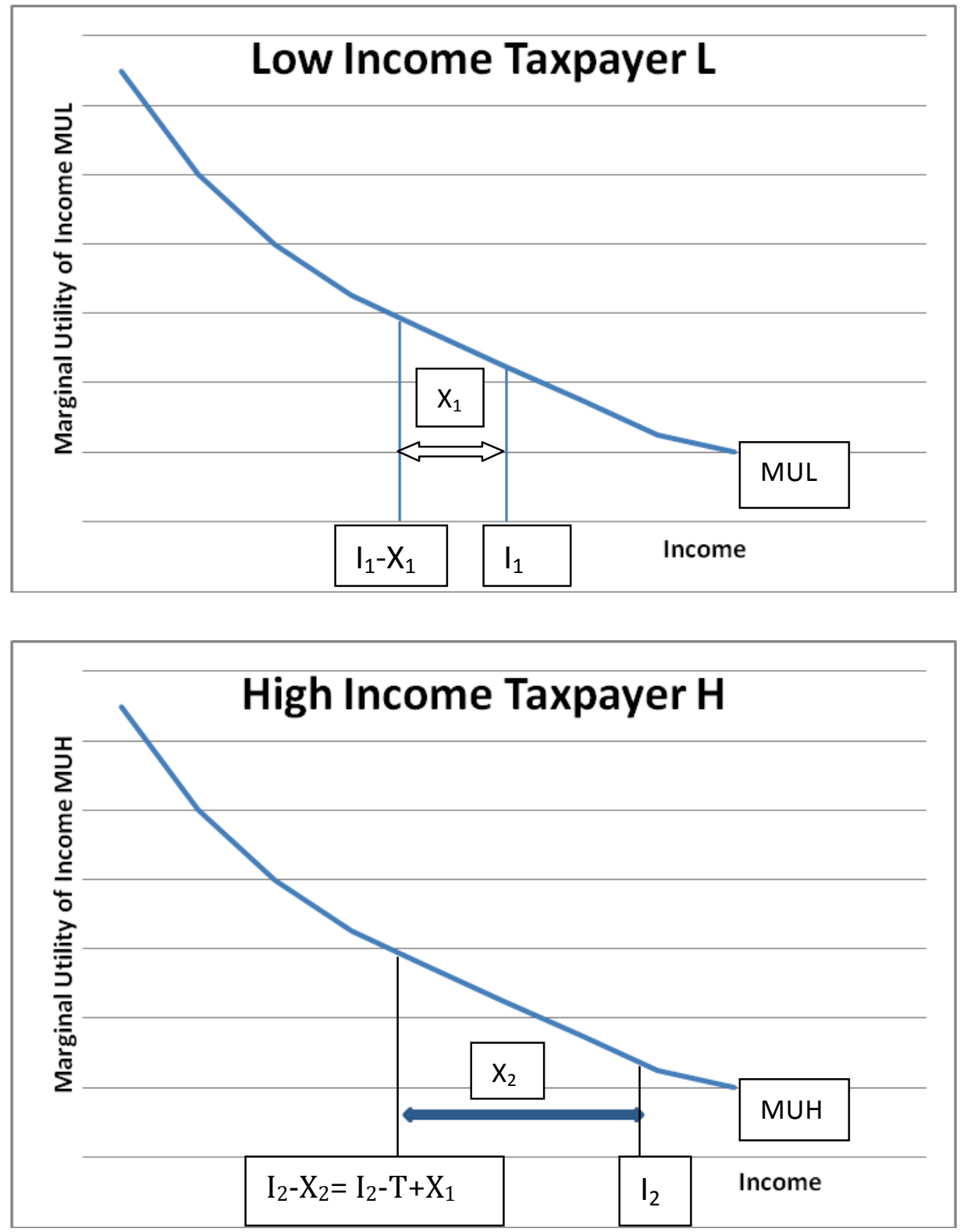

Suppose $X_{1}$ : Tax from taxpayer $L$ with income $I_{1}, X_{2}$ : Tax from taxpayer $H$ with income $I_{2}$, and the required revenue from taxes is $\mathrm{T}$.

$\mathrm{X}_{1}+\mathrm{X}_{2}=\mathrm{T} \rightarrow \mathrm{X}_{2}=\mathrm{T}-\mathrm{X}_{1}$.

The income after tax for the taxpayer with income $\mathrm{I}_{1} \rightarrow \mathrm{I}_{1}-\mathrm{X}_{1}$

And the income after tax for the taxpayer with income $\mathrm{I}_{2} \rightarrow \mathrm{I}_{2}-\mathrm{X}_{2}$, but $\mathrm{X}_{2}=\mathrm{T}-\mathrm{X}_{1}$

Thus, we can rewrite the income after tax for the taxpayer as $H \rightarrow I_{2}-T+X_{1}$

So, we can find the values of $X_{1}$ and $X_{2}$ using Integration:

$\int_{\mathrm{I} 1-\mathrm{X} 1}^{\mathrm{I} 1} M U L \cdot d I_{1}=\int_{\mathrm{I} 2-\mathrm{T}+\mathrm{X} 1}^{\mathrm{I} 2} M U H \cdot d I_{2}$ 
Special Case: If $M U L=M U H=\mathrm{C}$ (Which $\mathrm{C}$ denotes to a constant number), then (Note: $\mathrm{MU}$ Curve will be parallel to $\mathrm{X}$-axis):

$\int_{\mathrm{I} 1-\mathrm{x} 1}^{\mathrm{I} 1} C \cdot d I_{1}=\int_{\mathrm{I} 2-\mathrm{T}+\mathrm{X} 1}^{\mathrm{I} 2} C \cdot d I_{2} \rightarrow \mathrm{C}\left(\mathrm{I}_{1}-\mathrm{I}_{1}+\mathrm{X}_{1}\right)=\mathrm{C}\left(\mathrm{I}_{2}-\mathrm{I}_{2}+\mathrm{T}-\mathrm{X}_{1}\right)$

$\mathrm{X}_{1}=\mathrm{T}-\mathrm{X}_{1} \rightarrow \mathrm{X}_{1}=\mathrm{T} / 2---(4)$

Now $\mathrm{X}_{2}=\mathrm{T}-\mathrm{X}_{1} \rightarrow \mathrm{X}_{2}=\mathrm{T}-(\mathrm{T} / 2) \rightarrow \mathrm{X}_{2}=\mathrm{T} / 2----(5)$

Thus, the income after tax for the taxpayer with income Iin $\left(\mathrm{I}_{1}-\frac{T}{2}\right)$

Similarly, the income after tax for the taxpayer with income $\mathrm{I}_{2}$ is $\left(\mathrm{I}_{2}-\frac{T}{2}\right)$

If we assume that $I_{1}=500 \$, I_{2}=1000 \$$ and $T=100 \$$, then the required tax from the taxpayer with income I will be $\frac{\frac{T}{2}}{500}=10 \%$ of his income as a tax.

Similarly, the required tax from the taxpayer with income $\mathrm{I}_{2}$ will be $\frac{\frac{T}{2}}{1000}=5 \%$ of his income as a tax.

\subsection{Proportional Sacrifice}

If the tax burden is distributed proportionately to the loss, from Figure 1, the taxpayer $\mathrm{L}$ will pay $\mathrm{PB}$ and the taxpayer $\mathrm{H}$ will pay $\mathrm{P}^{\prime} \mathrm{B}$ ', i.e. $\mathrm{T}=\mathrm{PB}+\mathrm{P}^{\prime} \mathrm{B}$ ', the tax divided between the two taxpayers. Therefore, the loss of welfare to be lost for $\mathrm{L}$ (or PBDK / OBDM) are the same as in $\mathrm{H}$ (or P'B'D'K '/ O'B'D'M'). Under this rule, it is clear that the constant MU table will lead to the achievement of proportional taxation.

To find the values of $X_{1}$ and $X_{2}$, we can use Integration again (Figure 2):

$\frac{\int_{I_{1}-\mathrm{X}_{1}}^{\mathrm{I}_{1}} M U L \cdot d I 1}{\int_{0}^{\mathrm{I}_{1}} M U L \cdot d I 1}=\frac{\int_{\mathrm{I2}-\mathrm{T}+\mathrm{X} 1}^{\mathrm{I}} M U H \cdot d I 2}{\int_{0}^{I_{2}} M U H \cdot d I 2}$

If $M U L=M U H=\mathrm{C}(\mathrm{C}:$ constant number), then:

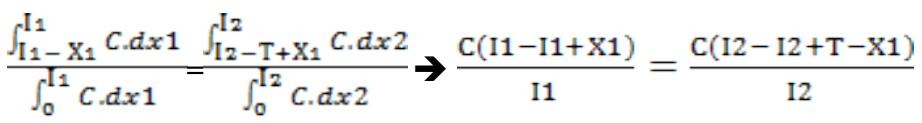

$\frac{X 1}{\mathrm{I} 1}=\frac{T-\mathrm{X} 1}{\mathrm{I} 2} \rightarrow \mathrm{X}_{1}=\frac{\mathrm{I} 1 T}{\mathrm{I} 1+\mathrm{I} 2}---(5)$

Now $\mathrm{X}_{2}=\mathrm{T}-\mathrm{X}_{1} \rightarrow \mathrm{X}_{2}=\mathrm{T}-\frac{I 1 T}{\mathrm{I} 1+\mathrm{I} 2} \rightarrow \mathrm{X}_{2}=\frac{I 2 T}{l 1+I 2}----(6)$

Thus, the income after tax for the taxpayer with income Iiis $\left(\mathrm{I} 1-\frac{I 2 T}{\mathrm{I} 1+\mathrm{I} 2}\right)$.

Similarly, the income after tax for the taxpayer with income $\mathrm{I}_{2}$ is $\left(\mathrm{I}_{2}-\frac{I 2 T}{I 1+I 2}\right)$.

If we assume that $I_{1}=500 \$, I_{2}=1000 \$$ and $T=100 \$$, then the required tax rate from the taxpayer with income I1 will be: $\frac{\frac{500(100)}{1500}}{500}=6.7 \%$. 
Similarly, the required tax rate from the taxpayer with income $\mathrm{I}_{2}$ will be $\frac{\frac{1000(100)}{1500}}{1000}=6.7 \%$.

\subsection{Marginal Sacrifice}

Under the marginal sacrifice rule, $\mathrm{L}$ pays $\mathrm{FB}$ and $\mathrm{H}$ pays $\mathrm{F}$ 'B, 'ie $\mathrm{T}=\mathrm{FB}+\mathrm{F}^{\prime} \mathrm{B}$ ', and the marginal loss of income will be $F G=F^{\prime} G{ }^{\prime}$. At the same time, the total loss of welfare for both taxpayers is given as FBDG + F'B' D'G '. The after-tax income is equivalent to $\mathrm{OF}=\mathrm{O}^{\prime} \mathrm{F}$.

To explain this rule suppose that the incomes of taxpayers $\mathrm{L} \& \mathrm{H}$ is $740 \$$ and $800 \$$ respectively, if the required tax returns is $50 \$$, then the full tax will be deducted from taxpayer $\mathrm{H}$ only. This is because $800 \$-50 \$>740 \$$. However, if the required tax returns is $80 \$$, then taxpayer $\mathrm{H}$ will pay $60 \$+\frac{20 \$}{2}=70 \$$, and taxpayer L will pay $\frac{20 \$}{2}=10 \$$. Therefore, we can simply observe that the tax rate applied in accordance with this rule is a progressive tax. This is because the tax rate for $\mathrm{H}$ is given as $=\frac{70 \mathrm{~s}}{800 \mathrm{~s}}=8.75 \%$ and for $\mathrm{L}=\frac{10 \mathrm{~s}}{740 \mathrm{~s}}=1.35 \%$.

According to this rule, we can derive the tax function for taxpayer $\mathrm{H}$. Thus, it can be formulated as shown below:

$\mathrm{T}_{\mathrm{H}}=\left\{\begin{array}{l}T \\ T_{1}+\frac{T 2}{2}, I_{2}-T \geq I_{1}-T<I_{1}\end{array}\right.$ where $\mathrm{I}_{2}$ is the income for taxpayer $\mathrm{H}, \mathrm{I} 2$ is the income for taxpayer $\mathrm{L}$, and $\mathrm{T}=\mathrm{T}_{1}+\mathrm{T}_{2}$.

Also the tax function for taxpayer $\mathrm{L}$ can be formulated as follows:

$\mathrm{T}_{\mathrm{L}}= \begin{cases}0 & , I_{2}-T \geq I_{1} \\ \frac{T 2}{2} & , I_{2}-T<I_{1}\end{cases}$

\section{Conclusion}

In conclusion, this paper provides a discussion of horizontal and vertical equity concepts mathematically. The paper gives examples to explain how to design tax rates. By comparing the results in each example, we saw that for both taxpayers $\mathrm{H}$ and $\mathrm{L}$ under the three rules above, the results of taxpayer $L$ under the marginal sacrifice rule is the best rule for him. This was followed by the proportional sacrifice rule and then the absolute sacrifice rule, and it is clear that the taxpayer $\mathrm{H}$ pays more than $\mathrm{L}$ regardless of the selected rule.

Under the vertical equity or "Equal Sacrifice Rules", this paper showed that taxpayers are treated equally if the loss of welfare is linked to loss of income. As a result, these rules may contribute to the design of the optimal tax system. 
Journal of Business Management and Economic Research, vol.2, issue.11, pp.16-23

\section{References}

Atkinson, A. B. (1970). On the measurement of inequality. Journal of Economic Theory 2:244-63.

Blackorby, D. \& Donaldson, D. (1976). Measures of equality and their meanings in terms of social welfare. University of British Columbia discussion paper, no. 76-20.

Feldstein, M. S. (1976). On the theory of tax reform. Journal of Public Economics 6, nos. 1-2: 77104.

Fields, G. S. \& Fei, J. C. H. (1978). On inequality comparisons. Econometrica 46, no. 2: 303-16.

Güneş, S.\& Polat, F. (2016). Tax Culture In The Context Of Development And Democratic Freedoms. European Scientific Journal, ESJ Special Edition, July: 1-17.

Holeckova, J. (2013). Comparison of the Tax Neutrality by Means of The Effective Tax Rates in the Czech Republic in the Years 2000-2010. European Scientific Journal, ESJ Special Edition, June no.1: 344-355.

King, M. A. (1983). An index of inequality: With applications to horizontal equity and social mobility. Econometrica 5 1, no. 1: 99-1 15.

Kondor, Y. (1975). Value judgements implied by the use of various measures of income inequality. Review of Income and Wealth 21: 309-21.

Mill, J. (1921). Principles of political Economy, edited by W.J. Ashley, London: Longmans, p. 804.

Moser, D.\& Evan, J., The Effects of Horizontal and Exchange Inequality on Tax Reporting Decisions, The Accounting Review Vol. 70 No.4 1995, pp.619-634

Obeid, R.\& Awad, B. (2018). Interaction of Monetary and Macro-prudential Policies: The Case of Jordan-Credit Gap as an Example. Asian Journal of Economics and Empirical Research, 5(1): 99-111.

Plotnick, R. (1981). A measure of horizontal inequity Review of Economics and Statistics 63, no. 2: 283-88.

Rosen, H. (1978). An approach to the study of income, utility, and horizontal equity. Quarterly Journal of Economics 92: 307-22

Sen, A. (1973). On economic inequality. Oxford: Clarendon Press.

Škreb, M. (1999). Economic Trends and Economic Policy, No. 73, 62-121.

Smith, A. (1776). An inquiry into the wealth of nations, 1904 ed. by E. Cunnan (Putnam's Sons, New York).

Tax Justice Network Africa (TJNA) (2011). "Addressing inequality In Africa Through Taxation." In M. Mutua, (Ed.) "A Citizen's Handbook on Taxation in Kenya." Nairobi: Institute of Economic Affairs.

Wise, K. \& Berger, N. (2010). Understanding Our Tax System: A Primer for Active Citizens. Massachusetts Budget and Policy Centre. Retrieved 23 February, 2015 from http://massbudget.org/report_window.php?loc=Tax_Primer_83110.html 